\title{
Microstructure-mechanical property relationships during processing of experimental Dual Phase (DP800) and TRIP 600 strip steels
}

\author{
V. Tzormpatzidi and G. Fourlaris
}

Laboratory of Physical Metallurgy, School of Mining and Metallurgical Engineering, National Technical University of Athens, 9 Heroon Polytechniou Street, 15780 Athens, GREECE.

Dual phase (DP) and Transformation Induced Plasticity (TRIP) steels belong to the family of advanced high strength strip steels (AHSS) [1]. These novel AHSS strip steel grades were developed to permit the down-gauging of car autobody (body-in-white), while providing high strength, suitable $\sigma_{0.2 \%} /$ tensile strength ratios, excellent formability and crash performance. Increased use of modern automobiles leads to the production of safe, fuel efficient and environmentally friendly vehicles [1].

The purpose of the present study is to devise suitable modified processing routes for two experimental AHSS grades, namely a DP800 and a TRIP 600 grades, with a view of producing via microstructural modification optimized in terms of mechanical properties strip steel products. The composition of the experimental steels studied is given in Table 1. DP800 steels have a nominal tensile strength of $800 \mathrm{MPa}$, while the corresponding strength of a TRIP600 grade would be $600 \mathrm{MPa}$. Intercritical annealing experiments were carried out in the DP800 grade within the temperature range of 750 to $875^{\circ} \mathrm{C}$, for time intervals ranging from 180 to 450 s followed by water quenching. Moreover, for the TRIP600 grade intercritical annealing experiments were carried out in the temperature range of 775 to $850^{\circ} \mathrm{C}$ for $2 \mathrm{~min}$, followed by isothermal bainitic transformation (in a molten lead/tin bath) at either 300,350 or $450^{\circ} \mathrm{C}$ for either 2 or $30 \mathrm{~min}$, followed by water quenching.

The microstructure of the as received DP800 steel is presented in Fig.1, while that of the as received TRIP600 is given in Fig. 2. It can be seen that the as received DP800 microstructure consists primarily of a mix of ferrite and martensite (37\% of the total microstructure), while the TRIP600 microstructure is an intricate mix of primarily ferrite, grain boundary bainite films and blocky residual austenite dispersions. Following intercritical annealing of the DP800 at $775^{\circ} \mathrm{C}$ for $180 \mathrm{~s}$ the mechanical properties of the modified DP800 steel are enhanced (i.e. higher elongation values coupled with an improved $\sigma_{0.2 \%} /$ tensile ratio of 0.48 , while maintaining a UTS value of $800 \mathrm{MPa}$ Fig.5). This has been attributed to the microstructural features of the modified DP800 product (Fig.3), i.e. refined low carbon martensite island dispersion present at ferrite/ferrite grain boundaries, with a martensite volume fraction of $39 \%$, permitting upon plastic deformation the preferential flow of ferrite grains around the non-deformable martensite islands. Similar attempts of enhancing the mechanical properties of the TRIP600 were met with less success, since a reduction in the overall elongation values of modified TRIP samples was noted, at all intercritical annealing and isothermal bainitic temperatures employed (Fig. 5), while modest improvements in the proof to tensile strength ratios were obtained. It is considered that the 'ideal' ratio of residual austenite/bainite aggregate and ferrite matrix has not been attained, as yet, on the TRIP600 grade (Fig.4).

The present study has demonstrated that under carefully controlled processing conditions, it is entirely feasible to obtain modified microstructures in DP800 grades with desirable mechanical 
properties suitable for automotive applications. Such a goal has not been accomplished for the TRIP600 grade, however, it was confirmed that current TRIP600 processing is essentially optimized.

\section{References}

[1] Bleck W, Papaefthymiou S, Frehn A: Steel Research International, 75 (11):704-710, 2004.

Table 1: Composition (wt \%) of DP800 and TRIP600 strip steels

\begin{tabular}{|c|c|c|c|c|c|c|c|c|c|c|c|}
\hline & $\mathrm{C}$ & $\mathrm{S}$ & $\mathrm{P}$ & $\mathrm{Mn}$ & $\mathrm{Si}$ & $\mathrm{N}$ & $\mathrm{Al}$ & $\mathrm{Nb}$ & $\mathrm{Cr}$ & $\mathrm{V}$ & $\mathrm{Ti}$ \\
\hline DP800 & 0.112 & 0.004 & 0.012 & 1.52 & 0.445 & 0.003 & 0.043 & 0.017 & 0.027 & 0.008 & 0.002 \\
\hline TRIP600 & 0.183 & 0.002 & 0.009 & 1.46 & 1.35 & 0.0037 & 0.139 & 0.001 & 0.025 & 0.002 & 0.015 \\
\hline
\end{tabular}

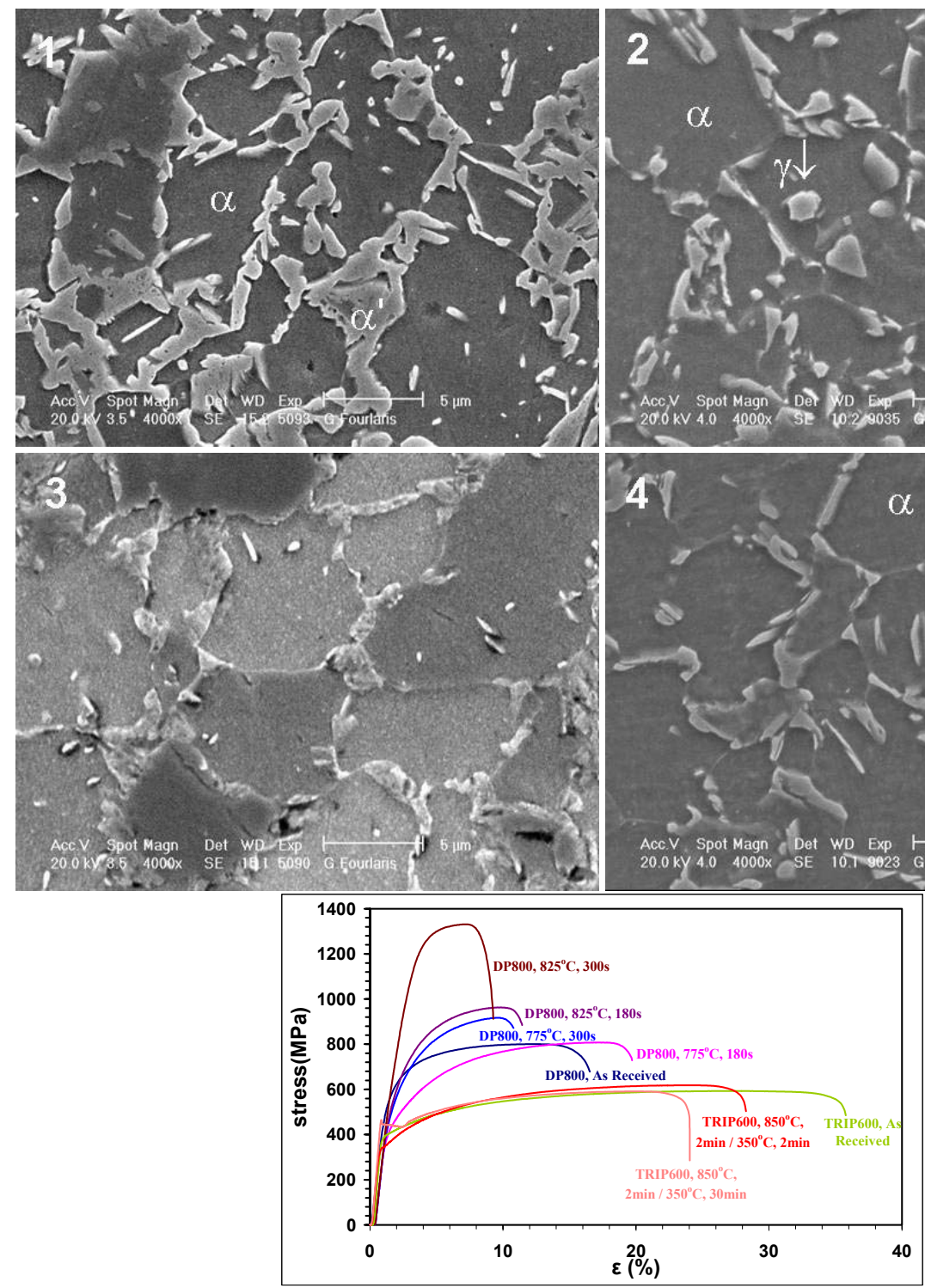

FIGS. 1\&2: SEM micrographs of DP800 (FIG.1) and TRIP 600 (FIG.2) in the as received condition.

FIGS. 3\&4: DP800 intercritically annealed at $775^{\circ} \mathrm{C}$ for $180 \mathrm{~s}$, water quenched (FIG.3) and TRIP600 intercritically annealed at $775^{\circ} \mathrm{C}$ for $2 \mathrm{~min}$, followed by isothermal transformation at $350^{\circ} \mathrm{C}$ for $2 \mathrm{~min}$ and water quenching (FIG.4).

FIG.5: Stress versus strain in heat treated DP800 and TRIP600 strip steels. 